\title{
Effect of Fresh Forage Canola on Production Performance and Egg Quality of Laying Hens
}

\author{
Yixiao Ma ${ }^{1}$, Qiaohua Wang ${ }^{1,2 *}$, Bo Wang ${ }^{3, *}$, Jie Kuai, ${ }^{3,4}$, Guangsheng Zhou ${ }^{3,4}$ and Tingdong $\mathrm{Fu}^{3,4}$ \\ ${ }^{1}$ College of Engineering, Huazhong Agricultural University, Wuhan, P. R. China \\ ${ }^{2}$ Key Laboratory of Agricultural Equipment in Mid-lower Yangtze River, Ministry of Agriculture and rural affairs; Wuhan, P. \\ R. China \\ ${ }^{3}$ College of Plant Science and Technology, Huazhong Agricultural University, Wuhan, P. R. China \\ ${ }^{4}$ MOA Key Laboratory of Crop Ecophysiology and Farming System in the Middle Reaches of the Yangtze River, Wuhan, P. R. \\ China
}

*For correspondence: wqh@mail.hzau.edu.cn; wangbo@mail.hzau.edu.cn

Received 30 November 2020; Accepted 12 January 2021; Published 16 April 2021

\begin{abstract}
Feed shortage had become a major factor constraining the development of animal husbandry. Forage canola has been found to be a potential feed crop due to its high yield and good quality. Therefore, this study mixed different proportions of forage canola to the diet of laying hens and all eggs were collected for analysis. Laying hens were divided into four groups according to the feeding amount of canola: $0 \mathrm{~kg}, 3 \mathrm{~kg}, 6 \mathrm{~kg}, 9 \mathrm{~kg}$, with 30 laying hens in each group. In the feeding trial, there was no negative effect on hen body weight, egg production, or overall egg quality. The results showed that Group B, C and D complete feed consumption is less than Group A. From the spectrum analysis, the trend of the Group A was different from that of the other three groups. After 35 days of rearing, the laying rate of the Group B and the Group C increased about $30 \%$ compared to 1 to 7 day. The weight of the Group B and Group C increased about 5\% compared with the initial period, while the Group A increased 0.6\% and the Group D increased by 3\%. The eggshell strength of the Group B and Group C also increased significantly. The contents of phosphorus and potassium in the Group B and C were higher than those in the Group A and Group D. The effects of canola to poultry diets is therefore of practical interest. This study will provide us a potential forage substance in laying hens production performance. (C) 2021 Friends Science Publishers
\end{abstract}

Keywords: Egg; Egg Production Rate; Egg Quality; Forage canola; Laying hens

\section{Introduction}

With the rapid development of animal husbandry, feed shortage has become one of the main factors limiting its sustainable development (Kerorsa 2019). With the rapid progress of rapeseed breeding, most of the cultivars used in the rapeseed production were with low content of erucic acid and glucosinolate in China, which guarantee the forage safety in animal husbandry (Shi et al. 2011).

In the context of such challenges, many scholars are interested in studying the development of new forages. Currently, canola meal $(\mathrm{CM})$ has been proposed as an alternative source of protein (Min et al. 2011; Wickramasuriya et al. 2015). There have been trials evaluating the use of $\mathrm{CM}$ as a substitute for soybean meal in broiler diets, but an appropriate number of enzymes must be added to improve feed digestion in chicken industry (Irani et al. 2012; Conradie et al. 2018). Canola had great potential as an alternative replacement to soybean meal in broiler diets and could be helpful in designing low-cost feed formulations that would improve growth performance and health status in poultry farming systems in the future (Disetlhe et al. 2018). With the improvement of rapeseed breeding, it was found that the content of crude protein was significantly increased. Canola also contains certain cellulose, crude fat, minerals, such as $\mathrm{Ca}, \mathrm{Fe}, \mathrm{P}, \mathrm{Mn}, \mathrm{Se}$ and $\mathrm{Mg}$ and various vitamins (Sinclair et al. 2012; Karlsson et al. 2016; Gidlund et al. 2017). Due to the characteristics of being easily planted, high yield and beneficial to the protection of cultivated land, it was regarded as high quality forage in China now (Zhang et al. 2019). The effects of canola to poultry diets is therefore of practical interest. This may be expected to reduce feed stress and this possibility has been confirmed in several researches in China (Jeroch et al. 2001; Yi et al. 2017). However, up to date, there are few reports on directly feeding leaves or stalks of fresh canola or the comparison of feeding effects in terms of egg yield and quality by adding different proportions of canola stalks to common diets. 
To illuminate this uncharted area, we mixed different proportions of forage canola to the diet of laying hens and analyzed the total egg yield and egg quality using sensory evaluation (Panaite et al. 2019), physicochemical methods (Lokaewmanee et al. 2010) and infrared spectroscopy (Nicolas et al. 2011). The objective of this study was to study the effects of forage canola on the production efficiency and egg quality of laying hen, which will provide us a potential forage substance in laying hens' production performance.

\section{Materials and Methods}

The experiment was approved by the Institutional Animal Care and Use Committee at Huazhong Agricultural University, Wuhan, China (HZAUCH-2017-011) and it was conducted in accordance with the National Institute of Health guidelines for the care and use of experimental animals.

\section{Animals, Treatments and Sample Collection}

The laying hens are Jingyang Chicken raised in Enshi, Hubei, China. All feeding trials took place at the poultry unit of Badong Experimental Farm. One hundred and twenty laying hens were divided into four groups randomly. Ten hens were caged individually as a replicate and each group has 3 replicates. Each group is provided with sufficient complete feed. The Group A was the control, which were fed the complete feed without fresh canola. The Group B, C and D were fed with complete feed by adding 3 $\mathrm{kg}, 6 \mathrm{~kg}$ and $9 \mathrm{~kg}$ fresh canola respectively.

During the test period, the hens were fed twice a day, freely drinking water, and the number of eggs laid, egg weight, feed intake, and growth of laying hens were recorded daily. The trial period was from August 1 to September 4 for a total of 35 days. Data was analyzed every week. All eggs laid in each period are tested.

The main component of the complete feed is show in Table 1. The added forage canola was Brassica napus L. cv. Huayouza 62 (Table 2), which was bred by Huazhong Agricultural University. Fresh leaves and/or stalks from the seedling stage to the initial flowering stage cultivated in the experimental field at Jingyang were used, which were mechanically pulverized into leaves and/or stalks with a length of 0.5 to $1.0 \mathrm{~cm}$ for digestion before feeding.

\section{Data collection}

Method for determination of visible near-infrared: Eggs were decontaminated with distilled water, dried naturally, and grouped by visible near-infrared spectroscopy (USB2000+, Ocean Optics). The fiber optic spectrometer was preheated for $30 \mathrm{~min}$, and each egg sample was repeatedly scanned five times to obtain an average spectral curve. In this experiment, Spec suite was used as the
Table 1: Main ingredients and nutrient levels of complete feed

\begin{tabular}{llll}
\hline composition & $\%$ & Nutritional level & $\%$ \\
\hline corn & 60 & Crude protein & 18.45 \\
Cardamom & 10 & ether extract & 3.46 \\
Wheat bran & 8 & Ash & 6.42 \\
shell & 7 & Crude fiber & 3.16 \\
Pine needle & 5 & Ca & 1.36 \\
Fish meal & 10 & $\mathrm{P}$ & 0.52 \\
\hline
\end{tabular}

Table 2: Canola Huaza 62 nutrition index in different periods

\begin{tabular}{llllllll}
\hline Period & CP & EE & Ash & NDF & ADF & Ca & $\mathrm{p}$ \\
\hline Seedling stage & $16.32 \mathrm{c}$ & $4.91 \mathrm{c}$ & $8.06 \mathrm{a}$ & $42.43 \mathrm{c}$ & $29.76 \mathrm{c}$ & $1.76 \mathrm{~b}$ & $0.44 \mathrm{c}$ \\
Grey moss period & $17.46 \mathrm{~b}$ & $5.87 \mathrm{~b}$ & $7.89 \mathrm{a}$ & $48.65 \mathrm{~b}$ & $36.16 \mathrm{~b}$ & $2.13 \mathrm{a}$ & $0.68 \mathrm{~b}$ \\
Florescence & $18.17 \mathrm{a}$ & $8.30 \mathrm{a}$ & $8.32 \mathrm{a}$ & $51.98 \mathrm{a}$ & $39.62 \mathrm{a}$ & $2.49 \mathrm{a}$ & $0.83 \mathrm{a}$ \\
\hline Note: Different letters within each column indicate a significant difference $(P<0.05)$
\end{tabular}

spectrum acquisition software. To avoid distortion of the collected spectral data, the integration time is set to $60 \mathrm{Ms}$. Each egg was spectrum scanned three times, with the smooth width at 3. Visible near-infrared spectroscopy was performed on all samples, and it was performed to obtain differences between the groups of eggs from the spectral characteristics.

\section{Determination of egg quality parameters}

An electronic balance was used to measure egg weight. The eggshell strength tester (FGV-10XY, Israel Oka Food Technology Co., Ltd.) measured the maximum pressure the eggshell could withstand per square centimeter. Egg Quality Analyzer (EA-01, Israel Oka Food Technology Co., Ltd.) was used to obtain the yolk color grade.

\section{Biochemical analysis}

The egg white yolk mixture was weighed and then nitric acid, perchloric acid, and sulfuric acid were added on a tunable electric furnace $\left(120-180^{\circ} \mathrm{C}\right)$ until the mixture was digested to a white smoke and was colorless, transparent or slightly yellow. A standard curve of phosphorus standard solution in the cuvette was made at a wavelength of $660 \mathrm{~nm}$. The phosphorus content of the liquid samples was determined and compared with the standard series to obtain the phosphorus concentration in the measurement liquid. The content of the phosphorus element was calculated according to the formula (1):

$$
x=\frac{\left(m_{1}-m_{0}\right) w_{P}}{m s v_{2}} \times \frac{100}{1000}
$$

Where $\mathrm{X}$ is phosphorus content in the sample / (mg/100 g); $\mathrm{m}_{1}$ : the mass of phosphorus in the sample solution for measurement $/(\mu \mathrm{g}) ; \mathrm{m}_{0}$ : mass of phosphorus in the blank solution for measurement/( $\mu \mathrm{g}) ; \mathrm{V}_{1}$ : digested liquid sample volumetric volume $/(\mathrm{mL})$; $\mathrm{m}$ : sample volume or transfer volume/(g); $\mathrm{V}_{2}$ : volume of sample digestive solution / $(\mathrm{mL})$; 100, 1000: conversion factor. 
Table 3: Feed intake of each group of hens after adding different proportions of feed rapeseed in the diet $(\mathrm{kg})$

\begin{tabular}{lllll}
\hline Composition & $\begin{array}{l}\text { Group A } \\
\text { (control) }\end{array}$ & $\begin{array}{l}\text { Group B } \\
\text { (add 3 kg) }\end{array}$ & $\begin{array}{l}\text { Group C } \\
\text { (add 6 kg) }\end{array}$ & $\begin{array}{l}\text { Group D } \\
\text { (add 9 kg) }\end{array}$ \\
\hline Complete feed & 0.131 & 0.100 & 0.096 & 0.083 \\
canola & $/$ & 0.100 & 0.178 & 0.181 \\
Total amount & 0.130 & 0.200 & 0.274 & 0.264 \\
\hline
\end{tabular}

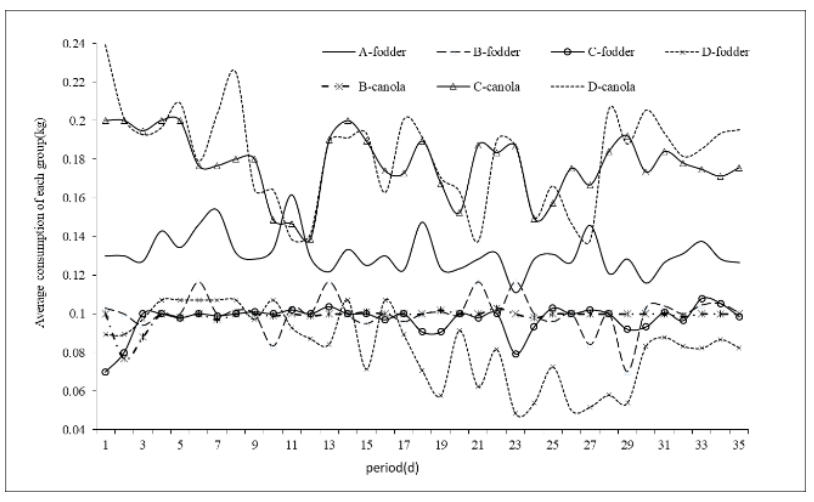

Fig. 1: Changes in feed intake of laying hens after adding different proportions of canola to diets

This figure mainly describes the daily consumption of each chicken in the four groups A, B, C and D. A-fodder represents the amount of complete feed consumed by Group A. B-fodder represents the amount of complete feed consumed by Group B. C-fodder represents the amount of complete feed consumed by Group C. D-fodder represents the amount of complete feed consumed by Group D. B-canola represents the amount of canola consumed by Group B. C-canola represents the amount of canola consumed by Group C. D-canola represents the amount of canola consumed by Group D

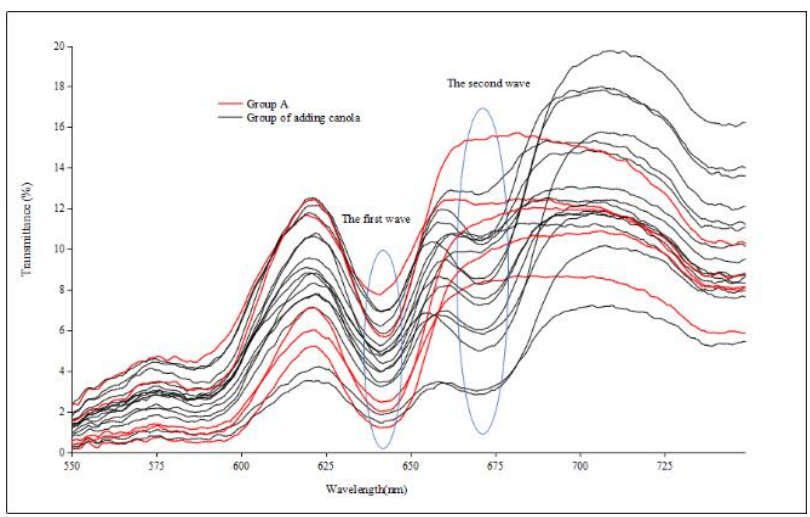

Fig. 2: Spectral changes of different groups after adding different proportions of feed canola to the diet

The red line in the figure indicates the spectral transmittance of Group A eggs. The spectral transmittance of eggs in the three Group B, Group C, and Group D is consistent, and they are all represented by black lines. The vertical dotted line indicates where the second trough appears

The content of potassium and calcium in the egg samples were determined. Samples were digested using the microwave digestion method. Under the same experimental conditions for measuring the standard curve working solution, the blank solution and the measuring solution were injected into an atomic absorption spectrometer, and the potassium and calcium absorbance was measured. The concentration of potassium and calcium in the liquid to be tested was obtained according to a standard curve. The potassium and calcium content were calculated according to the formula (2):

$$
x=\frac{\left(\rho-p_{0}\right) \operatorname{XvXf}}{m} \times \frac{100}{100 C}
$$

Where $\mathrm{X}$ is content of the measured element in the sample / (mg/100 g); $\rho$ : mass concentration of the element in the measuring solution / $(\mathrm{mg} / \mathrm{L}) ; \rho_{0}$ : determination of the mass concentration of the element in the blank test solution / $(\mathrm{mg} / \mathrm{L}) ; v$ : sample volume / (mL); m: mass of the sample / (g); $f$ : dilution factor of the sample; 100, 1000: conversion factor.

\section{Results}

\section{Dosage for each group}

Sufficient complete feed and different proportions of feed canola were provided to each group in the experiment. According to Fig. 1, the feed intake of complete feed in the Group A was between $0.120 \mathrm{~kg}$ and $0.140 \mathrm{~kg}$ per day. The feed intake of complete feed in the experimental group was about $0.10 \mathrm{~kg}$. The feed intake of complete feed gradually decreased with the passage of time. In terms of food consumption, the Group A consumed $0.130 \mathrm{~kg}$; the Group B consumed $0.200 \mathrm{~kg}$. And the Group C showed the largest consumption at $0.274 \mathrm{~kg}$, while the Group D consumed $0.264 \mathrm{~kg}$ (Table 3).

It is generally agreed that the huff unit is an important standard of egg freshness (Jones and Musgrove 2005). The eggs were all AA evaluated by Huff value. None of the results below will be biased by egg freshness.

\section{Analysis of visible near-infrared spectral characteristics}

It is interesting to note that, the eggs all showed the first wave trough at a wavelength of $625 \mathrm{~nm}$. The second wave trough appeared in the Group B, C and D at a wavelength of $675 \mathrm{~nm}$, while the Group A did not show a wave trough (Fig. 2). From the spectrum analysis, the trend of the Group A was different from that of the other three groups, and the trend of the waveforms of the three groups using canola was similar.

\section{Canola influence egg laying rate}

The change in the laying rate of hens after adding different proportions of canola to the diets of each group (Fig. 3), which showed that the laying rate of each group was about $30 \%$ at the 1-to-7-day stage from the start of the experiment, and there was no significantly difference between each group. From day $29^{\text {th }}$ to $35^{\text {th }}$, the laying rate of the Group A and the Group D was about 30\%, with no obvious increase between the laying rates of 1 to 7 day. The laying rate of the Group B and the Group C was about 30\% higher than that of 1 to 7 day. 


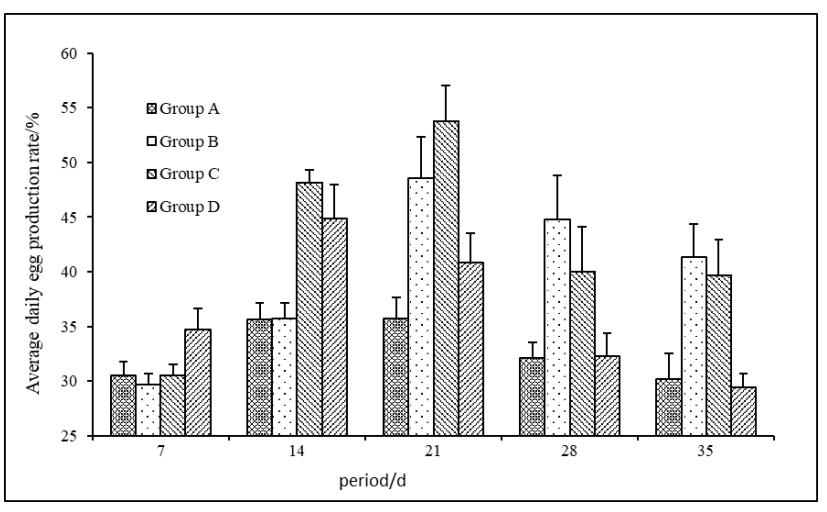

Fig. 3: Changes in egg production rate of laying hens after adding different proportions of canola to diet

Group A: feeding with no canola. Group B: feeding with $3 \mathrm{~kg}$ canola. Group C: feeding with $6 \mathrm{~kg}$ canola. Group D: feeding with $9 \mathrm{~kg}$ canola (the same as follows)

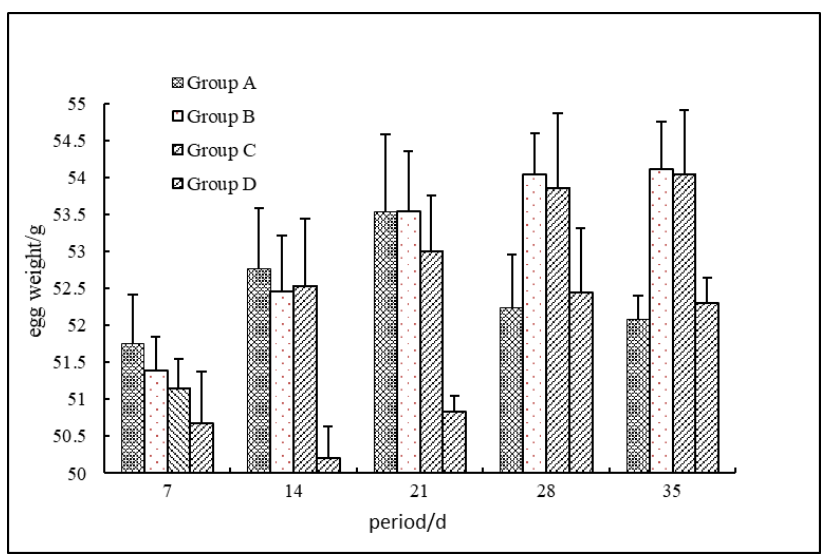

Fig. 4: Changes in whole egg weight after adding different proportions of canola to the diet

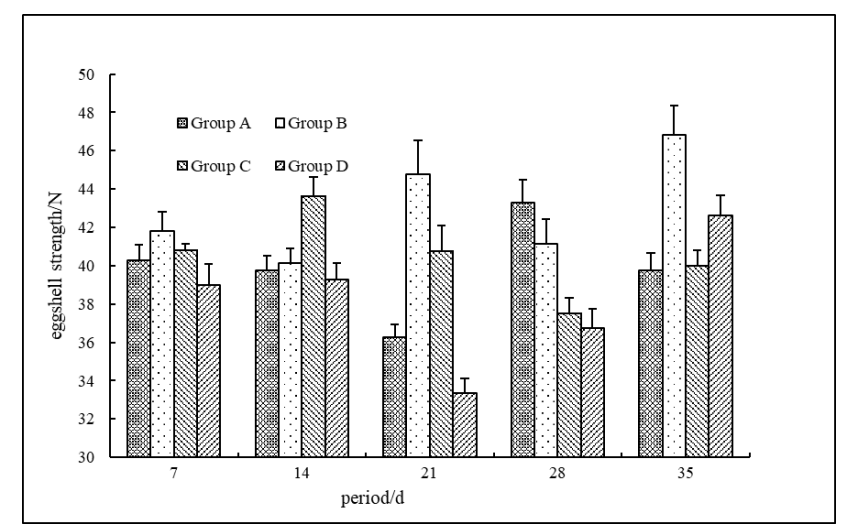

Fig. 5: Changes of eggshell strength after adding different proportions of canola to the diet

In addition, the whole egg weight of different groups showed no difference in 1 to 7 days (Fig. 4). By the end of the experiment, i.e., 29 to 35 days of feeding, the whole egg weight of each group showed an upward trend. Among the groups, the weight of the Group B and Group C increased by about $5 \%$ compared with the initial period, the Group A increased by $0.6 \%$, and the Group D increased by $3 \%$.

\section{Comparison of eggshell intensity with feeding different amounts of canola}

Eggshell strength is one of the most important factors in egg quality. The eggshell strength (Fig. 5) did not show any difference between groups at the first week $(P>0.05)$. At the later stage of the experiment, i.e., 29 to 35 days, the results showed that the eggshell strength of the Group B and Group C increased, but the Group D and the Group A did not change significantly, which indicated that adding an appropriate amount of canola could enhance the eggshell strength of laying hens.

\section{Comparison of egg yolk color with feeding different amounts of canola}

Eggshell color was significantly affected by feed (Kanda $e t$ al. 2009). Non-phytate phosphorus levels have an extremely significant interaction effect on egg yolk color (Nie et al. 2014). The color change of egg yolk after adding different proportions of canola to the diet (Fig. 6) was not significant $(P>0.05)$ after the preliminary experiment. The egg yolk color of the experimental group added with canola had changed compared with that of the Group A. With an increased time of feeding, there was no obvious change in the egg yolk color of Group A, whereas the egg yolk color of the test group gradually deepened with feeding time. By the end of the experiment, i.e., 29 to 35 days, the index color of the Group D was as dark as 12 and the color was positively correlated with the proportion of canola added to the basal diet.

\section{Comparison of trace element in eggs of hens fed canola}

In the first 1 to 7 days of the experiment, there was a significant difference in the phosphorus content between the Group D and the other three groups. During the test period, the content of phosphorus in the eggs of each group fluctuated, and the Group $\mathrm{C}$ was higher than the other groups. During 8 to 28 days, the Group $\mathrm{C}$ and the other three groups showed significant differences; at the end of the trial, i.e., 29 to 35 days, there was no significant difference in each group (Fig. 7).

The content of potassium in the diets was increased after adding different proportions of canola to the diet. The potassium content of the eggs in the Group B, C and D was higher than that in the Group A during the 15 to 35 days after feeding (Fig. 8).

In the first 1 to 7 days of the experiment, the content of calcium in the eggs of the Group A was significantly higher than that of the experimental group; there was no significant difference between the groups in the 8 to 14 days of the experiment. In the 15 to 21 days of the experiment, the 


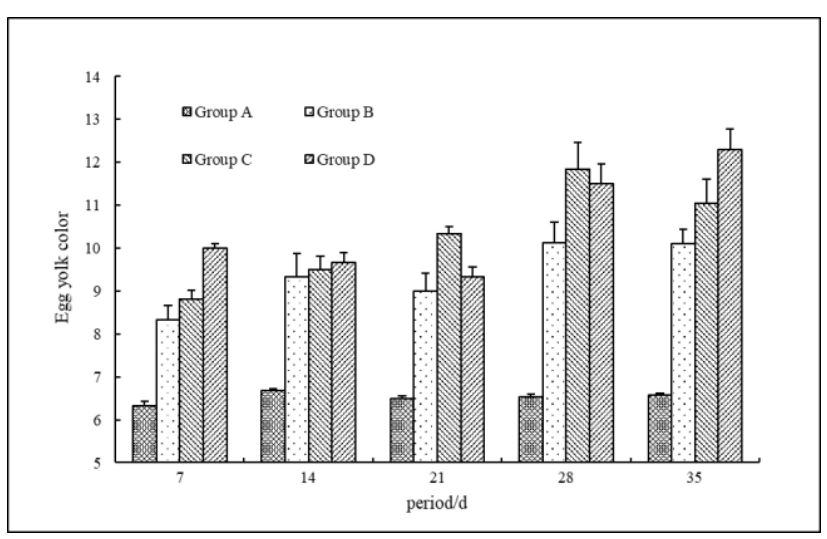

Fig. 6: Color change of egg yolk after adding different proportions of canola to grain

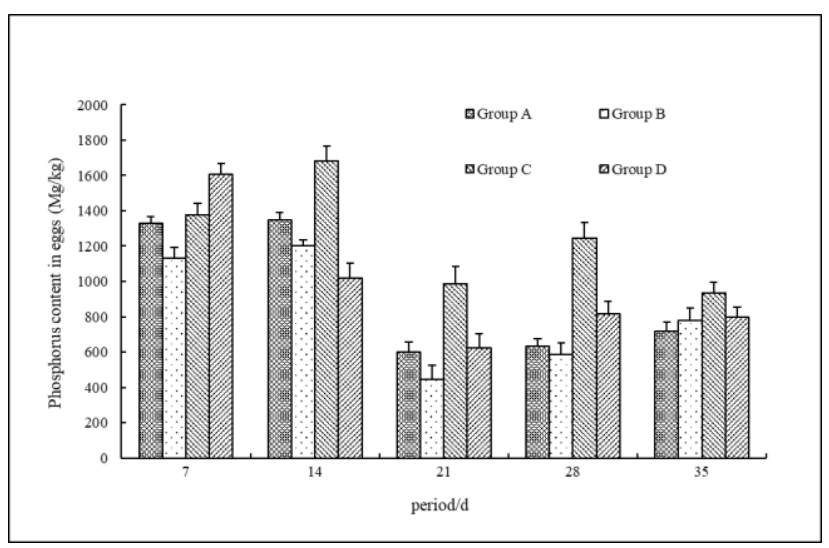

Fig. 7: Changes of phosphorus content in eggs after adding different proportions of canola to diet

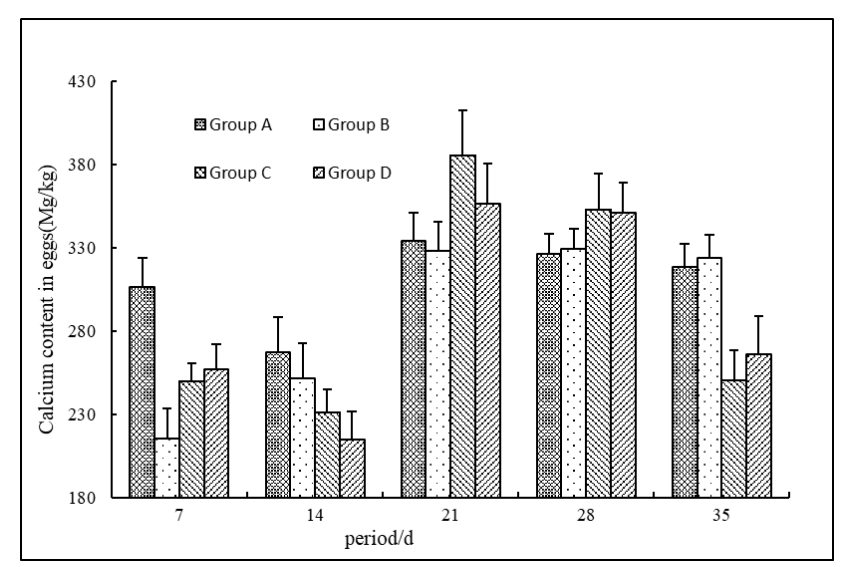

Fig. 8: Changes of calcium content in eggs after adding different proportions of canola to the diet

calcium content in the Group $\mathrm{C}$ and $\mathrm{D}$ increased, which was significantly higher than the Group A and B. On the 22 to the 35 days, the content of calcium in eggs in the Group $\mathrm{C}$ and $\mathrm{D}$ showed a downward trend, slightly higher than the Group A and Group B, and on the 29 to the 35 day, it was significantly lower than in the Group A and B (Fig. 9).

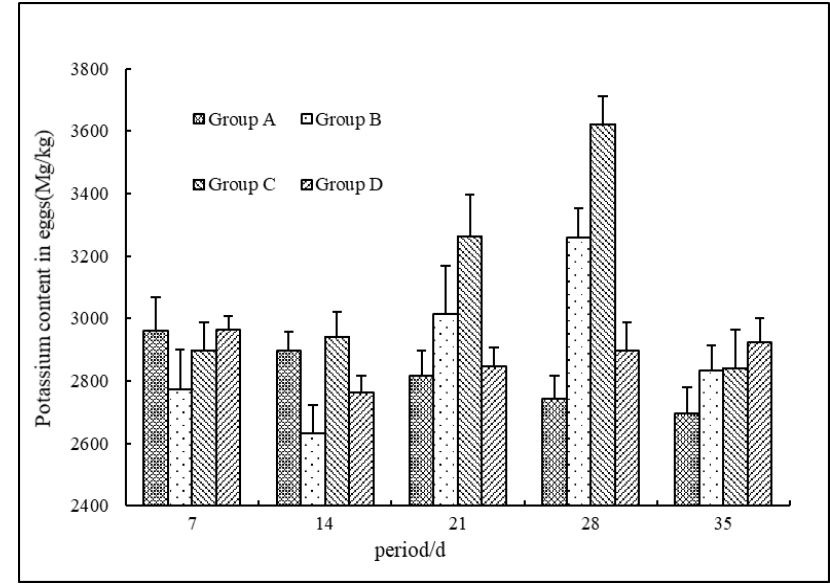

Fig. 9: Changes of potassium content in eggs after adding different proportions of canola to the diet

After feeding canola for 15 to 35 days, the contents of phosphorus and potassium in the Group B and $\mathrm{C}$ were higher than those in the Group A and Group D, indicating that the proper amount of feed canola can promote the accumulation of these nutrients in the eggs and improve the nutritional quality of the eggs.

\section{Discussion}

Feed intake is one of the most important indexes in this study because it is the basis to measure whether canola can be used as feed in laying hens. The high fiber content in canola reduces feed intake (Thacker and Widyaratne 2012). Thus, complete feed consumption in the Group B, C and D is less than Group A, which can reduce farming costs.

There was no obvious difference in the spectra of the Group B, C and D. The trend of the Group A was different at the $675 \mathrm{~nm}$, which showed that the difference in eggs was mainly caused by canola. By scanning the near-infrared spectrum of the sample, the characteristic information of the hydrogen-containing groups in the organic molecules in the sample can be obtained.

Laying hens in the canola experiment group (the Group B, C and D), consumed a large amount of food (Fig. 2), because the feed consumption of laying hens was closely related to the dietary energy and decreased with the increase of dietary energy (Ivy and Gleaves 1976). The energy content of canola of the same quality is lower than that of the complete feed, but the energy provided to laying hens is almost the same. Therefore, the amount consumed has little influence on the performance of the laying hens. Thus, the composition and structure of the eggs changed after the canola was digested and absorbed by laying hens.

There was a negative correlation between egg weight and egg number, so the two traits should be considered when comparing the effects of canola on the performance of production (Wu et al. 2009). The results showed that the 
laying rate could be increased by adding a proper amount of canola to the basic diet, while it could be decreased by adding too much canola. Overall, the Group B and the Group $\mathrm{C}$ not only increased the weight of eggs but also increased the number of laying hens, thus, the production efficiency of laying hens was improved significantly.

The eggshell strength of the Group B and the Group C was greater than that of the Group A (control), but the eggshell strength of the Group D was not significantly different from that of the control group. Compared with feeding only complete feed, adding canola to the diet increased the phosphorus content in the egg and the increase of phosphorus content increased the eggshell strength (Taylor 1965). However, when the phosphorus content is too high, the eggshell strength will decrease. It may be that the high level of phosphorus will hinder the reabsorption of bone calcium and interfere with calcium escaping from bone into the blood, thus affecting the formation of eggshells, which is more serious than the consequences caused by the lack of phosphorus (Wang 2010). In this study, the Group B of laying hens ate more canola than the Group A, but less available phosphorus was obtained compared with the Group C and D. However, the eggshell strength of the Group B was significantly higher than that of the other three groups, which indicated that the feeding level of the Group B was optimum in eggshell strength traits.

The results showed that the addition of canola might have some influence on the carotene in egg yolk. With the increase of canola dosage, egg yolk color gradually deepened, which showed that the absorption of rich nutrients is promoted in the eggs of laying hens fed canola.

Mohammad et al. (2018) found that there was no significant difference in trace elements in the egg to produce contents of the feed-fed laying hens with large differences. It can be seen from Fig. 7 and 8 that there are large changes in phosphorus and calcium in the four groups of eggs in different period, but the difference between the four groups is not significant. In Fig. 9, there is a significant difference in 21 to 28 days, but the difference is not significant in the 28-to-35-day period and there are some changes in the waveform in this period in Fig. 7 and 8, which may due to the high temperature in this cycle caused stress response of laying hens.

\section{Conclusion}

This aspect of the research suggested that feeding laying hens with the proper amount of forage canola has no toxic side effects, and its growth and development have no harmful effects. The study found that when each laying hen was fed with $0.10 \mathrm{~kg}$ of canola and $0.10 \mathrm{~kg}$ of complete feed, the egg yield, storage quality and nutritional quality were the optimum. Collectively, forage canola can provide the necessary nutrients for the egg production of laying hens. This may be considered a promising aspect of feed substitutes.
Future research should consider the potential effects of the digestive system of laying hens more carefully. And we do not know that feed canola can be used as fodder for other poultry or not, such as ducks. This is an issue for future research to explore.

\section{Acknowledgements}

This study was supported by National Natural Science Foundation of China (31871863), Technical Innovation Project in Hubei Province (2017ABA064) and the Fundamental Research Funds for the Central Universities (2662017JC005).

\section{Author Contributions}

Wang Qiaohua and Wang Bo designed the experiment and revise the manuscript. Ma Yixiao collected and analyzed the data and prepared the manuscript. Fu Tingdong helped designing the experiment. Kuai Jie and Zhou Guangsheng helped interpret the results. All authors read and approved the final manuscript.

\section{Conflict of Interest}

The authors declare that the research was conducted in the absence of any commercial or financial relationships that could be construed as a potential conflict of interest.

\section{Data Availability}

All datasets presented in this study will be available on a fair request to the corresponding authors

\section{Ehics Approval}

The approved protocol of the Institutional Animal Care and Use was applied in all animal handling procedures.

\section{References}

Conradie TA, E Pieterse, K Jacobs (2018). Application of Paracoccus marcusii as a potential feed additive for laying hens. Poult Sci 97:986-994

Disetlhe ARP, U Marume, V Mlambo (2018). Humic acid and enzymes inclusion in canola-based diets generate different responses in growth performance, protein utilization dynamics, and hematobiochemical parameters in broiler chickens. Poult Sci 97:2745-2753

Gidlund H, M Hetta, P Huhtanen (2017). Milk production and methane emissions from dairy cows fed a low or high proportion of red clover silage and an incremental level of rapeseed expeller. Livest Sci 197:73-81

Irani M, N Ilia, M Yousefian, H Abedi, S Gharaveysi (2012). Canola meal as a source of feedstuff in formulated diets for broiler production after incorporation with digestive enzymes. Ind $J$ Anim Sci 82:1062-1066

Ivy RE, EW Gleaves (1976). Effect of egg production level, dietary protein and energy on feed consumption and nutrient requirements of laying hens. Poult Sci 55:2166-2171 
Jeroch H, W Kracht, S Dnicke (2001). Feeding value of rape products and its improvement for broilers and laying hens. Eur J Lipid Sci Technol 103:7-11

Jones DR, MT Musgrove (2005). Effects of extended storage on egg quality factors. Poult Sci 84:1774-1777

Karlsson J, M Patel, K Holtenius (2016). Replacing cereals and soybean meal with sugar beet pulp and rapeseed meal or distiller's grain in grass silage diets to dairy cows. Rapport $166: 82-86$

Kanda, LM Sawitree, K Panuwat, Y Koh-En (2009). Effects of dietary mulberry leaves (Morus Alba L.) on egg yolk color. J Poult Sci 46:112-115

Kerorsa GB, TI Dula, GT Chewaka (2019). Major Constraints of livestock development studied in Lalo Kile District, Kellem Wollega Zone, Ethiopia. Intl J Agric Agribus 6:35-41

Lokaewmanee K, KE Yamauchi, T Komori, T Komori, K Saito (2010). Effects on egg yolk colour of paprika or paprika combined with marigold flower extract. Ital J Anim Sci 9:356-359

Min YN, Z Wang, C Coto, F Yan, S Cerrate, FZ Liu, PW Waldroup (2011). Evaluation of canola meal from biodiesel production as a feed ingredient for broilers. Intl J Poul Sci 10:363-374

Mohammad H, A Sadeghi, M Dankob, M Aminzare, M Raeisi, HH Miri, M Saghi (2018). The impact of strain and feed intake on egg toxic trace elements deposition in laying hens and its health risk assessment. Environ Monit Assess 190:540-548

Nicolas AN, M Ngadi, S Prasher, Y Karimi (2011). Prediction of egg freshness and albumen quality Using visible/near infrared spectroscopy. Food Bioprocess Technol 4:731-736

Nie W, Y Ying, J Yuan, W Zhong, Y Guo (2014). Effect of dietary nonphytate phosphorus on laying performance and small intestinal epithelial phosphate transporter expression in Dwarf pink-shell laying hens. J Anim Sci Biotechnol 4:34-40
Panaite TD, S Mironeasa, M Iuga, PA Vlaicu (2019). Liquid egg products characterization during storage as a response of novel phytoadditives added in hens' diet. Emir J Food Agric 31:304-314

Shi C, WD Xu, QR Yu, HZ Zhang, ZW Yang, JG Wu (2011). Impacts of erucic acid and glucosinolate content on genetic relationships between protein content and fatty acids of rape seed across environments. Euphytica 180:337-346

Sinclair L, C Blake, P Griffin, G Jones (2012). The partial replacement of soybean meal and rapeseed meal with feed grade urea or a slowrelease urea and its effect on the performance, metabolism and digestibility in dairy cows. Animal 6; Article 920

Taylor TG (1965). Dietary phosphorus and egg shell thickness in the domestic fowl. Brit Poult Sci 6:79-87

Thacker P, G Widyaratne (2012). Effects of expeller pressed camelina meal and/or canola meal on digestibility, performance and fatty acid composition of broiler chickens fed wheat-soybean meal-based diets. Arch Anim Nutr 66:402-415

Wang X (2010). Effects of nutritional factors on eggshell quality. Chin Anim Poult Seed Indust 6:128-130

Wickramasuriya SS, YJ Yi, J Yoo, NK Kang, JM Heo (2015). Erratum to: a review of canola meal as an alternative feed ingredient for ducks. $J$ Anim Sci Technol 57:29-39

Wu G, MM Bryant, P Gunawardana, DA Roland (2009). Effect of nutrient density on performance, egg components, egg solids, egg quality, and profits in eight commercial leghorn strains during phase one. Poul Sci 86:691-697

Yi SF, H Yang, LF Yu (2017). Study on fresh feed Brassica Napus L. on fattening effects in beef cattle. Chin Feed, 20:39-40

Zhang HH, YX Liang, L Zhang, ZH Zeng, X Li, YH Li, CT Huang, XM Zhang, SX Yang (2019). Amino acid composition and nutritional evaluation of double low rapeseed proteins. Food Ferment Indust 45:235-241 